Article

\title{
Joint Inventory and Pricing Policy for an Online to Offline Closed-Loop Supply Chain Model with Random Defective Rate and Returnable Transport Items
}

\author{
Biswajit Sarkar $^{1}\left(\mathbb{D}\right.$, Mehran Ullah $^{1}\left(\mathbb{D}\right.$ and Seok-Beom Choi ${ }^{2, *}$ \\ 1 Department of Industrial \& Management Engineering, Hanyang University, Ansan Gyeonggi-do 15588, \\ Korea; bsarkar@hanyang.ac.kr (B.S.); mehrandirvi@gmail.com (M.U.) \\ 2 Department of International Business, Cheju Halla University, Jeju-do 63092, Korea \\ * Correspondence: sbchoi@cau.ac.kr; Tel.: +82-10-3854-2765
}

Received: 14 April 2019; Accepted: 20 May 2019; Published: 1 June 2019

check for updates

\begin{abstract}
Environmental deterioration is one of the current hot topics of the business world. To cope with the negative environmental impacts of corporate activities, researchers introduced the concept of closed-loop supply chain (CLSC) management and remanufacturing. This paper studies joint inventory and pricing decisions in a multi-echelon CLSC model that considers online to offline (O2O) business strategy. An imperfect production process is examined with a random defective rate that follows a probability distribution. The results show that the $\mathrm{O} 2 \mathrm{O}$ channel increases the profit of the system. For the defective rate, three different distributions are considered and three examples are solved. The results of the three examples conclude that the highest profit is generated when the defective rate follows a uniform distribution. Furthermore, based on the salvage value of defective items, two cases were studied. Results and sensitivity analysis show that the increase in defective rate does not reduce total profit in every situation, as perceived by the existing literature. Sensitivity analysis and numerical examples are given to show robustness of the model and draw important managerial insights.
\end{abstract}

Keywords: CLSC management; $\mathrm{O} 2 \mathrm{O}$ channel; random defective rate; hybrid manufacturingremanufacturing strategy

\section{Introduction}

The widespread usage of the internet and competitive business environment have resulted in the development of a dual channel sales strategy called the O2O strategy [1]. Companies are integrating online and offline sales channels to compete in the market by increasing service level, and to attract more demand. The literature termed integrating offline and online channels as a multi-channel context [2]. Traditional enterprises can deliver diverse types of products and services by incorporating online sales channels for their businesses. The number of companies taking advantage of this opportunity is increasing. This enables potential customers to browse the catalogs, price information, availability of the products, and even order the products before visiting the physical stores. Therefore, online sales channels can improve the sales of physical (offline) stores. A case study conducted by Chang et al. [3] provided factual proof that integrating offline and online sales channels increases the sales order. However, $\mathrm{O} 2 \mathrm{O}$ sales channel requires the customer acquisition cost to convince the potential consumer or customer to purchase a specific product; literature considers this cost a primary business metric for $\mathrm{O} 2 \mathrm{O}$ channeling. It determines the worth of the end customer to the business and, through it, the return on investment from the customers can be obtained. This enables businesses to 
analyze their investment decisions on a single customer to improve profitability [4]. Organizations make investments for online marketing and offline marketing of their products. Then, to compute the customer acquisition cost, each customer, who buys the product or service, is asked about the channel of information through which he came to know about that product. In this way, organizations collect a handful of data for a specific period and calculate customer acquisition cost for both types of channels.

Empirical evidence shows that the $\mathrm{O} 2 \mathrm{O}$ channel plays a vital role for value creation in the business strategy [4]. However, $\mathrm{O} 2 \mathrm{O}$ brings many management complexities and costs into supply chain management. These costs include online and offline marketing investments, subsidies, commissions, administration costs, and bonuses. Successful investment in $\mathrm{O} 2 \mathrm{O}$ channeling is directly associated with future corporate profits. It increases customer retention and expands market shares by capturing new customers [5]. To incorporate an e-commerce strategy, this study considers a supply chain management model that captures extra market demand through the $\mathrm{O} 2 \mathrm{O}$ channel and considers the required investment and maintenance cost for the $\mathrm{O} 2 \mathrm{O}$ channel. In this context, this paper studies joint inventory and pricing decisions in a multi-echelon closed-loop supply chain management with remanufacturing and returnable transport items (RTI). Even though many papers had explored CLSC management, they either did not focus on $\mathrm{O} 2 \mathrm{O}$ or they did not consider all other important features such as the consideration of transportation packaging management. In fact, from our literature review, we find that none of the existing studies examine the packaging management system and investment decisions in a CLSC system with $\mathrm{O} 2 \mathrm{O}$ channel. Notice that the most closely related paper is Sarkar et al. [6], however, they did not consider dual-channel structure. Furthermore, they also neglect defective production and assume that all the produced products are perfect items, which is an unrealistic assumption. Moreover, they only studied inventory policies and considered constant demand, while this paper studies joint inventory and pricing policies with price and investment dependent demand.

\section{Literature Review}

This section gives an overview of the existing literature relevant to this paper. This paper contributes to research in the field of CLSC management, O2O channel in CLSC management, and RTI management and design, therefore, we focus on the related literature in these three areas.

Because of the increasing appreciation of environmental sustainability, CLSC management becomes a very important topic. More specifically, the remanufacturing process has grown into a big business. According to Bulmus et al. [7], \$43 billion valued products were sold from remanufacturing used products in the U.S. in 2011. Many giant well-established enterprises, including Xerox, Kodak, and $\mathrm{HP}$, have extensively incorporated their remanufacturing processes into their regular production lines and operations [8]. Research in this field dates back to the 1960s, with the first work reported from Schrady [9]. This paper studied an inventory model with single manufacturing batch followed by many repair batches, this policy is called (R, I) policy. Later on, Richter [10] and Richter [11] extended Schrady's model and introduced a hybrid manufacturing-remanufacturing system. According to Richter assumptions, market demand is fulfilled by manufacturing new products from raw material, and by repairing used products. Continuing his work, Richter [12] found that a complete recovery or complete disposal is the optimal choice. Many others extended this work with similar results including Richter and Dobos [13], Dobos and Richter [14], and Dobos and Richter [15]. Maiti and Giri [16] considered the used product quality in CLSC management and examined analytical models in five different scenarios including the centralized, vertical Nash, and three decentralized cases. Recently, Moshtagh and Taleizadeh [17] considered return rate with quality and used three distinct distributions to model the return rate. Tian and Zhang [18] considered disassembly scheduling and pricing of returned goods with price based yield. For a more comprehensive review of CLSC management, it is suggested that readers study Govindan and Soleimani [19] and Diallo et al. [20].

Today, with the progress of the Internet, online shopping is gaining popularity; the consumer buys products both through online and offline channels. The online purchasing channel has various 
advantages such as energy and time savings. Consumers can also compare the product prices among different websites and choose the best product. However, some customers like to observe, feel and examine finished products before buying, which could not be accomplished without the traditional offline channel. Therefore, organizations operate both the channels to get the associated advantages. Many business giants like Lenovo, Sony, IBM, Dell, Nike, and HP use this dual-channel policy to improve their sales [21-23]. In the literature, many articles have examined the impact of introducing the online channel on performances of companies and supply chain management. For example, Tsay and Agrawal [24] examined the channel coordination policies to reduce channel disputes between supply chain members. Yao and Liu [25] used Stackelberg and Bertrand games to investigate channel conflict and competition among suppliers and retailers. Huang and Swaminathan [26] and Yan [27] also used game theory to investigate optimal pricing decisions in $\mathrm{O} 2 \mathrm{O}$ supply chain management. Dan et al. [28] studied dual-channel supply chain management with retailer manipulation of the retail services; they found that the optimal pricing strategies can be affected by retail service. Huang et al. [22] considered pricing policies for an $\mathrm{O} 2 \mathrm{O}$ supply chain management including demand disruptions. Li et al. [29] reviewed the difference between single-channel and dual-channel supply chain management. The $\mathrm{O} 2 \mathrm{O}$ business model is characterized by high transportation demand because of last mile supply systems; furthermore, the returns from CLSC model also increase the transportation demand of the system; therefore, energy efficient transportation becomes a primary part of $\mathrm{O} 2 \mathrm{O}$ supply chain. Bányai et al. [30] and Bányai [31] studied energy efficiency in first mile and last mile logistics systems. Despite all these excellent research works, papers that deal with product remanufacturing, reuse, and transportation packaging with the imperfect production system in the $\mathrm{O} 2 \mathrm{O}$ supply chains are sparse in the literature. This study bridges this gap by studying a dual-channel CLSC model with remanufacturing, and returnable transport items considering random imperfection in the production system.

Solid waste generation is one of the main environmental threats posed by supply chain management [32,33]. RTIs are used by organizations to reduce solid waste of supply chain management $[34,35]$. In addition, disposable packaging also increases the cost of the product. Livingstone and Sparks [36] stated that packaging is responsible for $10-40 \%$ of product prices. Moreover, RTI also increases the protection and security of the finished products and improves working conditions and manual handling [37]. Historically, these RTIs were studied independently from inventory management, for a detailed review, readers may study [38]. Nevertheless, contemporary research recognized packaging as a vital component of supply chain inventory management. In this regard, [39] studied RTI and inventory policies jointly. They investigated a two-level CLSC inventory management and used RTIs to transport finished goods among supply chain members. Glock and Kim [40] studied RTI and inventory management in a single-vendor multi-retailer CLSC structure. They also considered RTI design and considered RTI size and the required number of RTIs as decision variables. Sarkar et al. [6] extended Glock and Kim [40] with RTI design and management policy in hybrid manufacturing-remanufacturing CLSC management. Others, for example, Kelle and Silver [41] proposed several methods to forecast the expected demand and returns of RTI; and Goh and Varaprasad [42] developed a system for evaluating the container return distribution by considering RTIs shrinkage.

Many authors, for example,Lee [43], Gupta and Chakraborty [44], and Tayi and Ballou [45] studied imperfect items in inventory models. Among these, the last two did not consider shortages due to reworking. Lee et al. [46] and Glock and Jaber [47] presented imperfect production models without considering rework of defective products. Salameh and Jaber [48] studied an inventory model for imperfect quality items where these items are withdrawn from stock, resulting in lower holding cost per unit time. Jaber et al. [49] consider policies for handling imperfect quality products. Ouyang et al. [50] and Cárdenas-Barrón [51] developed inventory models and considered back ordering, while Eroglu and Ozdemir [52] considered shortages. Ben-Daya [53] likewise extended the inventory model with planned maintenance schedules. Sarkar et al. [54] considered quality of products in multi-echelon supply chain model. Sarkar [55] provided different approaches for defective product management. 
An improved way to calculate imperfect items is given by Kim et al. [56], and Sett et al. [57] determined optimal buffer inventory in imperfect production system. Sarkar et al. [58] studied warranty, optimal run time with inspection errors in the imperfect production system, and Kang et al. [59] discussed optimal ordering policies for the imperfect production system. Recently, Khanna et al. [60] considered two-level credit policies with imperfect quality, Tayyab et al. [61] considered process uncertainty, and Tayyab et al. [62] studied the multistage imperfect production system. The majority of the existing literature considered rework or scrap option for defective items, however, this paper considers salvage option for defective items.

\section{Problem Definition}

This paper considers a three-layer dual-channel hybrid CLSC model with RTI design and management. The manufacturer fulfills market demand through multiple retailers. To increase market share, each retailer opens an online selling channel, for which the retailer pays information cost and transportation cost. Furthermore, the demand rate jointly depends on finished product price and investment in the online channel. The manufacturer produced two types of products, the manufactured products from raw material, and the remanufactured products from used products collected from consumers. An imperfect production system is considered where the perfect items are sold into the primary market, and the defective items are marketed into a secondary market with a lower price. Finished products are transported in reusable secondary packages called RTIs that are owned by a third party logistics (3PL) provider. The 3PL also collects used products from the end customer and delivers them to the manufacturer for remanufacturing. The whole scenario is depicted in Figure 1.

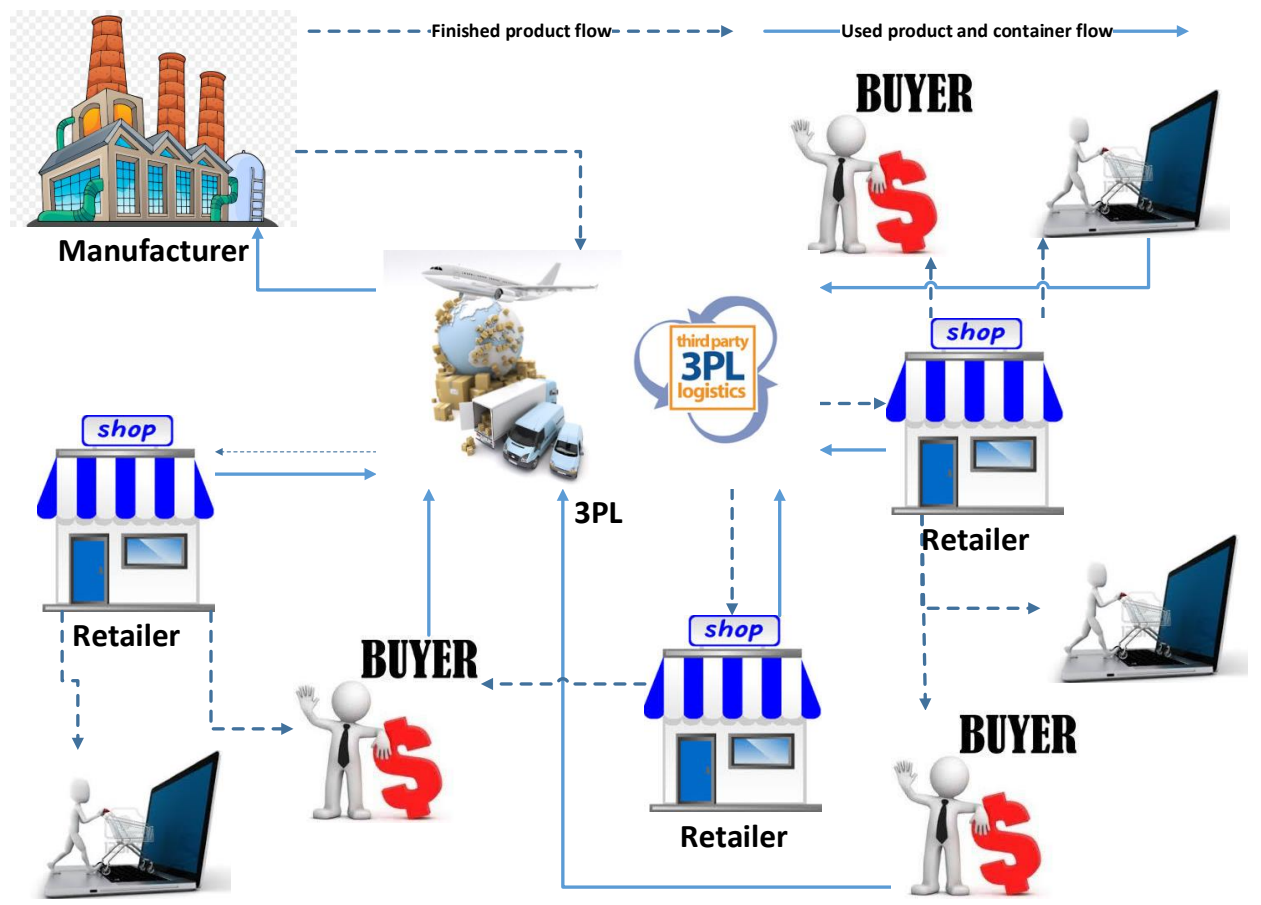

Figure 1. Logistics diagram of the proposed closed-loop supply chain (CLSC).

It is assumed that the total initial deterministic demand (offline market share) for the $i^{\text {th }}$ retailer is $a_{i}$, which follows demand price sensitivity, $b$, in a linear relationship. Other possible relationships, in which the demand function can be modeled, are quadratic and exponential. However, linear demand curves are widely used in the literature because of their simplicity and more importantly their sufficiency to catch important managerial implications. Thus, the total price-dependent deterministic demand at the $i^{\text {th }}$ retailer is $a_{i}-b p$. Now we consider the second part of demand, the online channel 
demand; which for the $i^{\text {th }}$ retailer can be given as $k \mathrm{IN}_{i}$. Where $k$ is the parameter and $\mathrm{IN}_{i}$ is the potential demand. Thus the net realized demand at retailer $i$ is $d_{i}=a_{i}-b p+k \mathrm{IN}_{i}$. It is obvious that the maximum price in the market would be $p=a / b$.

\section{Mathematical Model}

This paper considered a centralized supply chain system. To model the proposed centralized system, this section first calculates total revenue of the supply chain followed by the cost of individual player and, finally, the net profit is calculated by subtracting the costs of all players from total revenue.

\subsection{Total Revenue of the Supply Chain}

The proposed system generates revenue by selling the finished products of perfect quality in the dual-channel primary market and imperfect items in the secondary market. Total revenue can be expressed mathematically as,

$$
R E V=\sum_{i=1}^{n} p d_{i}+\mathrm{cw} r \sum_{i=1}^{n} d_{i}
$$

The first term in (1) shows revenue generated by $n$ retailers, while the second term shows revenue generated from selling imperfect items.

\subsection{Retailer's Model}

Total cost of the $i^{\text {th }}$ retailer consists ordering $\operatorname{cost} \frac{A_{i}}{T}$, holding cost $\frac{d_{i} h_{i}}{2}$, which can be calculated from Figure 2. Investment or information cost of $\mathrm{O} 2 \mathrm{O}$ channel $\frac{I N_{i}}{T}$, and transportation cost for the proposed $\mathrm{O} 2 \mathrm{O}$ channel $\frac{T R_{i}}{T}$ are also part of retailer cost function. For $n$ retailers the total cost can be stated as,

$$
\mathrm{TC}_{1}=\sum_{i=1}^{n} \frac{A_{i}+\mathrm{IN}_{i}+\mathrm{TR}_{i}}{T}+\sum_{i=1}^{n} \frac{1}{2} T d_{i} h_{i}
$$

\subsection{Manufacturer's Model}

The manufacturer produces finished products based on the market demand in a single setup per cycle, for which the setup cost per unit time is $\frac{S_{m}}{T}$. In each cycle, the manufacturer orders used products, for which the ordering cost is $\frac{A_{m}}{T}$. The manufacturer inventory diagram is shown in Figure 2, the holding cost for the finished product is formulated in Appendix A.1 and can be written as follows,

$$
h_{f} \sum_{i=1}^{n-1} d_{i+1} l_{i}+\frac{d^{2} T}{2(1-r) P_{m}} .
$$

The manufacturer inspects each product for which total inspection cost is $\operatorname{ck} \sum_{i=1}^{n} d_{i}$, and $h_{u} d \tau\left(1-\frac{\sum_{i=1}^{n} d_{i}}{2(1-r) P_{m}}\right)$ is the holding cost of used products. During production, $r \%$ of the total items produced are defective, to avoid shortages the manufacturer outsources the defective quantity with total cost $o w * r * \sum_{i=1}^{n} d_{i}$. $\tau d$ is the remanufactured quantity and $d(1-\tau)$ is the quantity of new products. Therefore, the cost of remanufacturing used products is $b d \tau\left(C_{r}\right)$, and the cost of manufacturing is $C_{m} d(1-\tau)$. The finished products quality is $0<q \leq 1$, to attain this quality, the manufacturer total quality cost is $d(1-\tau) q^{2} C_{q}$ for manufacturing and $d \tau C_{q}\left(q^{2}-q_{r}^{2}\right)$ for remanufacturing. The manufacturer incurs goodwill lost cost for producing low quality products which is $d g(1-q)$. Finally, the total emission cost from production activities can be expressed as $e_{m} \sum_{i=1}^{n} C_{\mathrm{ec}} d_{i}$. Hence, the total cost per unit time for the manufacturer $\left(T C_{2}\right)$ can be expressed as follows: 


$$
\begin{aligned}
T C_{2} & =\frac{A_{m}+S_{m}}{T}+h_{f}\left(\sum_{i=1}^{n-1} l_{i} \sum_{k=i+1}^{n} d_{k}+\frac{d^{2} T}{2(1-r) P_{m}}\right)+(\mathrm{ck}+o w * r) \sum_{i=1}^{n} d_{i}+h_{u} d \tau\left(1-\frac{\sum_{i=1}^{n} d_{i}}{2(1-r) P_{m}}\right) \\
& +d(1-\tau) C_{m}+d \tau C_{r}+d \tau C_{q}\left(q^{2}-q_{r}^{2}\right)+d q^{2}(1-\tau) C_{q}+d g(1-q)+e_{m} \sum_{i=1}^{n} C_{\mathrm{ec}} d_{i} .
\end{aligned}
$$

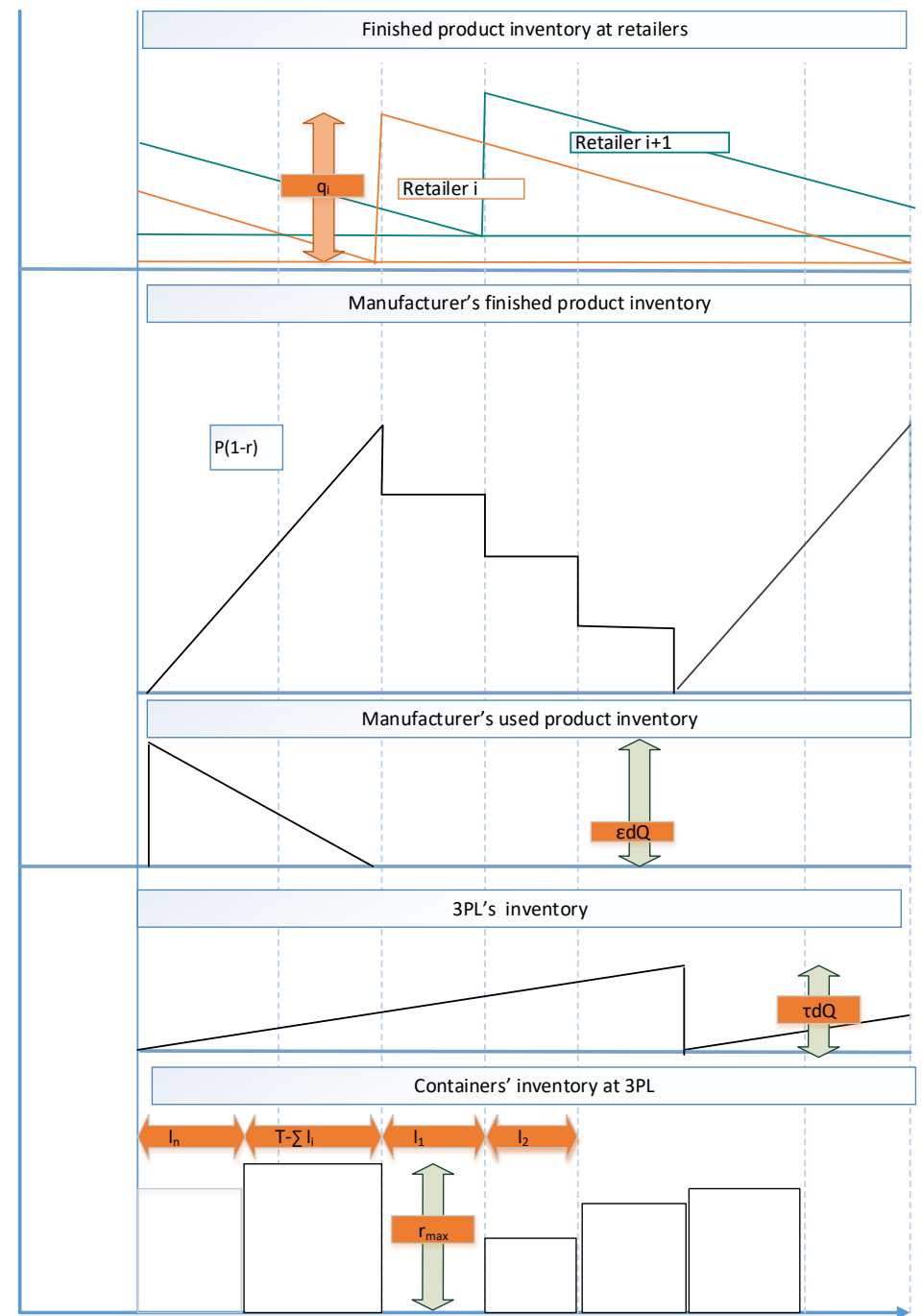

Figure 2. Logistics diagram of the proposed CLSC.

\subsection{PL's Model}

3PL's total cost comprises of collection setup cost per cycle $\frac{S_{3}}{T}$. The collection cost paid to customers is $\tau A_{t} \sum_{i=1}^{n} d_{i}$. The average holding cost of used product at 3PL is $h_{u} \frac{1}{2} d \tau T$. 3PL also provides transportation services, total transportation cost comprised of three parts: (1) finished products transportation from manufacturer to retailer $i,\left(\frac{d_{i} l_{i m}}{\lambda}\right)$, (2) empty RTI transportation from retailer $i$ to $3 \mathrm{PL} \frac{d_{i} l_{i j}}{\lambda}$, and (3) used products transportation from 3PL to manufacturer $\frac{d l_{\mathrm{m}}}{\lambda}$. For $n$ retailers total transportation cost is the sum of forward and reverse transportation costs represented by $C_{t}\left(\sum_{i=1}^{n} \frac{d_{i} l_{i j}}{\lambda}+\sum_{i=1}^{n} \frac{d_{i} l_{i m}}{\lambda}+\frac{d l_{\mathrm{jm}}}{\lambda}\right)$. Holding cost of RTIs is given by $h_{R}\left(\sum_{i=1}^{n} \frac{l_{i}\left(d_{\max }-d_{i}\right)}{\lambda}+\frac{d_{1}\left(T-\sum_{i=1}^{n} l_{i}\right)}{\lambda}\right)$, see Appendix A.2. RTI management cost is $C_{\lambda} d_{\max } \lambda^{s-1}$. For setting up collection centers and arranging the inspection system for determining the quality of the EOL/EOU products, 3PL makes an initial investment which can be expressed mathematically as $\frac{\gamma \tau^{2}}{T}$. Finally, 3PL's cost also consists of emissions cost from transportation, which is determined based on the traveled distance, and emissions from 
fuel required per unit distance for a specific truck is considered to model transportation emissions. Therefore, total emissions due to transportation between retailer $i$ and manufacturer $m$ can be modeled as $\frac{d_{i} l_{m}}{t_{c}}\left(e_{r} g_{m}\right)$, similarly emissions from transportation between retailer $i$ and 3PL $j$ can be written by $\left.\frac{d_{i} l_{i j}}{t_{c}}\right) e_{r} g_{m}$, and emissions from 3PL $j$ to manufacturer $m$ is given by $\frac{d \tau l_{j m}}{t_{c}}$. Now for $n$ retailers, a manufacturer, and a 3PL, total emission cost from transportation can be expressed mathematically as $\left(C_{\mathrm{ec}} e_{r} g_{m}\right)\left(\sum_{i=1}^{n} \frac{d_{i} l_{i m}}{t_{c}}+\sum_{i=1}^{n} \frac{d_{i} l_{i j}}{t_{c}}+\frac{d \tau l_{j m}}{t_{c}}\right)$. Total cost per unit of time for the 3PL $T C_{3}$ comprises of the above parts and can be expressed as,

$$
\begin{aligned}
T C_{3}= & \frac{S_{3}}{T}+\tau A_{t} \sum_{i=1}^{n} d_{i}+\frac{d \tau T h_{u}}{2}+C_{t}\left(\sum_{i=1}^{n} \frac{d_{i} l_{i j}}{\lambda}+\sum_{i=1}^{n} \frac{d_{i} l_{i m}}{\lambda}+\frac{d l_{\mathrm{jm}}}{\lambda}\right)+C_{\lambda} d_{\max } \lambda^{s-1} \\
+ & h_{R}\left(\sum_{i=1}^{n} \frac{l_{i}\left(d_{\max }-d_{i}\right)}{\lambda}+\frac{d_{1}\left(T-\sum_{i=1}^{n} l_{i}\right)}{\lambda}\right)+c_{d}(\tau-\tau) d+\frac{\gamma \tau^{2}}{T}+C_{\mathrm{ec}} e_{r} g_{m} \\
& \sum_{i=1}^{n} \frac{\tau d_{i} l_{i j}}{t_{c}}+C_{\mathrm{ec}} e_{r} g_{m} \sum_{i=1}^{n} \frac{d_{i} l_{i m}}{t_{c}}+\frac{d \tau C_{\mathrm{ec}} e_{r} g_{m} l_{\mathrm{jm}}}{t_{c}}
\end{aligned}
$$

\subsection{Net Profit of the Supply Chain}

Net profit of the supply chain can be calculated by subtracting cost of retailer (2), cost of manufacturer (3), and cost of 3PL (4) from total generated revenue (1), such that

$$
\Pi=\operatorname{Rev}-T C_{1}-T C_{2}-T C_{3}
$$

Using the transformation from demand function, total profit can be expressed as follows,

$$
\begin{aligned}
& \Pi=\operatorname{cwr} \sum_{i=1}^{n}\left(a_{i}-b p+k \mathrm{IN}_{i}\right)+\sum_{i=1}^{n} p\left(a_{i}-b p+k \mathrm{IN}_{i}\right)-\left(\sum_{i=1}^{n} \frac{T h_{i}}{2}\left(a_{i}-b p+k \mathrm{IN}_{i}\right)+\sum_{i=1}^{n}\right. \\
& \left.\frac{A_{i}+\mathrm{IN}_{i}+\mathrm{TR}_{i}}{T}\right)-\left(h_{f}\left(\sum_{i=1}^{n-1} l_{i}\left(a_{i+1}-b p+k \mathrm{IN}_{i}\right)+\frac{T\left(\sum_{i=1}^{n}\left(a_{i}-b p+k \mathrm{IN} \mathrm{N}_{i}\right)\right)^{2}}{2(1-r) P_{m}}\right)+\frac{A_{m}+S_{m}}{T}\right. \\
& +h_{u} \sum_{i=1}^{n} \tau\left(a_{i}-b p+k \mathrm{IN}_{i}\right)\left(1-\frac{\sum_{i=1}^{n}\left(a_{i}-b p+k \mathrm{IN}_{i}\right)}{2(1-r) P_{m}}\right)+((\mathrm{ck}+o w * r)) \sum_{i=1}^{n} a_{i}-b p+k \mathrm{IN}_{i}+\left(C_{m} * 1-\tau\right. \\
& \left.\sum_{i=1}^{n}\left(a_{i}-b p+k \mathrm{IN}_{i}\right)\right)+\tau C_{q} \sum_{i=1}^{n}\left(q^{2}-q_{r}^{2}\right)\left(a_{i}-b p+k \mathrm{IN}_{i}\right)+\left(\tau \sum_{i=1}^{n} C_{r}\left(a_{i}-b p+k \mathrm{IN}_{i}\right)\right)+\left(C_{q}\right. \\
& \left.\left.q^{2}(1-\tau) \sum_{i=1}^{n}\left(a_{i}-b p+k \mathrm{IN}_{i}\right)\right)+e_{m} \sum_{i=1}^{n} C_{\mathrm{ec}}\left(a_{i}-b p+k \mathrm{IN}_{i}\right)+\sum_{i=1}^{n} g(1-q)\left(a_{i}-b p+k \mathrm{IN}_{i}\right)\right) \\
& -\left(\tau A_{t} \sum_{i=1}^{n}\left(a_{i}-b p+k \mathbf{I N}_{i}\right)+\frac{T}{2}\left(\tau h_{u} \sum_{i=1}^{n}\left(a_{i}-b p+k \mathbf{I N}_{i}\right)\right)+\frac{S_{3}}{T}+C_{t}\left(\sum_{i=1}^{n} \frac{l_{i m}\left(a_{i}-b p+k \mathbf{I N}_{i}\right)}{\lambda}\right.\right. \\
& \left.+\sum_{i=1}^{n} \frac{\tau l_{i j}\left(a_{i}-b p+k \mathrm{IN} \mathrm{N}_{i}\right)}{\lambda}+\frac{l_{\mathrm{im}} \sum_{i=1}^{n} \tau\left(a_{i}-b p+k \mathrm{IN}_{i}\right)}{\lambda}\right)+\left(C_{\lambda} \lambda^{s-1}\left(a_{\max }-b p+k \mathrm{IN}_{a_{\max }}\right)\right) \\
& +\frac{h_{R}\left(\left(T-\sum_{i=1}^{n} l_{i}\right)\left(a_{\max }-b p+k \mathrm{IN}_{\operatorname{amax}}\right)\right)}{\lambda}+\frac{\gamma \tau^{2}}{T}+C_{\mathrm{ec}} e_{r} g_{m} \sum_{i=1}^{n} \frac{\tau l_{i j}\left(a_{i}-b p+k \mathrm{IN} \mathrm{N}_{i}\right)}{t_{c}}+C_{\mathrm{ec}} e_{r} g_{m} \\
& \left.\sum_{i=1}^{n} \frac{l_{i m}\left(a_{i}-b p+k \mathbb{N}_{i}\right)}{t_{c}}+\frac{\sum_{i=1}^{n} \tau C_{\mathrm{ec}} e_{r} g_{m} l_{\mathrm{im}}\left(a_{i}-b p+k \mathrm{IN}_{i}\right)}{t_{c}}\right)
\end{aligned}
$$

Assuming $T, \lambda, \tau$, and $p$ as any real nonzero numbers, then, $\exists$ a unique $T^{*}, \lambda^{*}, \tau^{*}$ and $p^{*}$ that maximizes the total profit and satisfies the following first-order conditions (FOC):

$$
\begin{aligned}
& \frac{\partial(\Pi)}{\partial p}=0 \\
& \frac{\partial(\Pi)}{\partial \tau}=0 \\
& \frac{\partial(\Pi)}{\partial T}=0 \\
& \frac{\partial(\Pi)}{\partial \lambda}=0 .
\end{aligned}
$$


Furthermore, $(\Pi)$ is concave, if and only if at $T^{*}, \lambda^{*}, \tau^{*}$ and $p^{*}$ the hessian of $(\Pi)$ is negative semidefinite.

Proof. See Appendix B for the proof of concavity of objective function.

Until now, the model considers random defective rates of production, but no probability distribution is considered. Now, one can test the model under different distributions: uniform, triangular, and beta. Thus, if $r$ follows a uniform distribution, then the probability density function $f(r)$ for the uniform distribution with parameter $x$ and $y$ is,

$$
f(r)= \begin{cases}\frac{1}{x-y} & x \leq r \leq y \\ 0 & \text { otherwise }\end{cases}
$$

and its expected value is $E[r]=\frac{y+x}{2}$.

Similarly, if $r$ follows a triangular distribution, then the probability density function for the triangular distribution with parameter $x, z$, and $y$ is

$$
f(r)= \begin{cases}0 & r<x \\ \frac{2(r-x)}{(y-x)(z-x)} & x \leq r<z \\ \frac{2}{(y-x)} & r=z \\ \frac{2(y-r)}{(y-x)(y-z)} & z<r \leq y \\ 0 & y<r\end{cases}
$$

and its expected value is $E[r]=\frac{x+y+z}{3}$.

Finally, if $r$ follows a beta distribution, then the probability density function for the beta distribution with parameter $\lambda$ and $\beta$ is

$$
f(r)= \begin{cases}\frac{r^{\lambda-1}(1-r)^{\beta-1}}{B(\lambda, \beta)} & \lambda>0, \beta>0,0 \leq r<1\end{cases}
$$

and its expected value is $E[r]=\frac{\lambda}{\lambda+\beta}$.

\subsection{Solution Procedure}

Our aim is to derive the optimal values of the decision variables and maximize the total net profit under all the three distributions. The solution procedure is as follows:

Step 1.0 Select the distribution function.

Step 1.1 Plug the expected value of $r$ in (5).

Step 2.0 Set $\tau=0, \lambda=1$, and $T=1$ find $p^{*}$ from FOC given in (6).

Step 2.1 Using $p=p^{*}, \lambda=1$, and $T=1$ find $\tau^{*}$ from FOC given in (7).

Step 2.2 Using $p=p^{*}, \lambda=1$, and $\tau=\tau^{*}$ find $T^{*}$ from FOC given in (8).

Step 2.3 Using $p=p^{*}, T=T^{*}$, and $\tau=\tau^{*}$ find $\lambda^{*}$ from FOC given in (9).

Step 2.4 Using $\tau=\tau^{*}, \lambda=\lambda^{*}$, and $T=T^{*}$ find $p^{*}$ from FOC given in (6).

Step 2.5 Using $p=p^{*}, \lambda=\lambda^{*}$, and $T=T^{*}$ find $\tau^{*}$ from FOC given in (7).

Step 2.6 Using $p=p^{*}, \lambda=\lambda^{*}$, and $\tau=\tau^{*}$ find $T^{*}$ from FOC given in (8).

Step 2.7 Using $p=p^{*}, T=T^{*}$, and $\tau=\tau^{*}$ find $\lambda^{*}$ from FOC given in (9).

Step 2.8 Repeat Steps $2.4-2.7$ until the values of $\tau^{*}, \lambda^{*}, T^{*}$, and $p^{*}$ stop changing.

Step 2.9 Update the optimal values $\tau^{*}, \lambda^{*}, T^{*}$, and $p^{*}$.

Step 3.0 Set $\lambda=\left\lfloor\lambda^{*}\right\rfloor$, calculate total profit from (5). 
Step 4.0 Set $\lambda=\left\lceil\lambda^{*}\right\rceil$, calculate total profit from (5).

Step 5.0 If $\Pi\left(\tau^{*},\left\lfloor\lambda^{*}\right\rfloor, T^{*}, p^{*}\right)<\Pi\left(\tau^{*},\left\lceil\lambda^{*}\right\rceil, T^{*}, p^{*}\right)$, update $\lambda^{*}=\left\lfloor\lambda^{*}\right\rfloor$, else update $\lambda^{*}=\left\lceil\lambda^{*}\right\rceil$.

Step 5.1 Repeat Steps 2.4-2.6 until the values of $\tau^{*}, T^{*}$, and $p^{*}$ stop changing.

Step 6.0 Find total profit from (5).

Step 7.0 Repeat the process for all the three probability distributions.

\section{Numerical Experiment}

The developed model is tested with numerical experiment and sensitivity analysis of the input parameters. The numerical experiment considers a three-layer supply chain network consisting of four retailers, a manufacturer, and a 3PL. The values of input parameters are obtained from [6] and are given in Table 1.

Table 1. General Input parameter values for numerical examples.

\begin{tabular}{ll|ll|ll|ll|ll|ll|ll|ll}
\hline$A_{m}$ & 20 & $S_{3}$ & 10 & $n$ & 4 & $\gamma$ & 2000 & $A_{t}$ & 20 & $C_{\lambda}$ & 0.5 & $h_{R}$ & 5 & $s$ & 2 \\
$C_{m}$ & 110 & $C_{r}$ & 84 & $C_{q}$ & 5 & $q_{r}$ & 0.3 & $g_{m}$ & 0.25 & $e_{r}$ & 0.01 & $C_{\mathrm{ec}}$ & 18 & $g$ & 10 \\
$C_{t}$ & 0.004 & $l_{\mathrm{jm}}$ & 50 & $t_{c}$ & 80 & $e_{m}$ & 0.002066 & $P_{m}$ & 10,000 & $h_{f}$ & 5.2 & $h_{u}$ & 2.5 & $S_{m}$ & 60 \\
$l_{1}$ & 0.009 & $l_{2}$ & 0.008 & $l_{3}$ & 0.007 & $l_{4}$ & 0.008 & $l_{m}$ & 373 & $l_{2 m}$ & 226 & $l_{3 m}$ & 216 & $l_{4 m}$ & 371 \\
$l_{j}$ & 373 & $l_{2 j}$ & 226 & $l_{3 j}$ & 216 & $l_{4 j}$ & 371 & $h_{1}$ & 8. & $h_{2}$ & 7.4 & $h_{3}$ & 8.2 & $h_{4}$ & 8.1 \\
$A_{1}$ & 63 & $A_{2}$ & 51 & $A_{3}$ & 39 & $A_{4}$ & 63 & $\mathrm{IN}_{1}$ & 500 & $\mathrm{IN}_{2}$ & 489 & $\mathrm{IN}_{3}$ & 623 & $\mathrm{IN}_{4}$ & 585 \\
$\mathrm{TR}_{1}$ & 300 & $\mathrm{TR}_{2}$ & 283 & $\mathrm{TR}_{3}$ & 250 & $\mathrm{TR}_{4}$ & 310 & $a_{1}$ & 1200 & $a_{2}$ & 720 & $a_{3}$ & 520 & $a_{4}$ & 600 \\
$b$ & 0.9 & $q$ & 0.9 & $\mathrm{ck}$ & 5 & $\mathrm{cw}$ & 200 & $k$ & 0.4 & $x$ & 0.15 & $y$ & 0.4 & $z$ & 0.2 \\
$\lambda$ & 0.15 & $\beta$ & 0.4 & $\mathrm{ow}$ & 115 & & & & & & & & & & \\
\hline
\end{tabular}

The optimal results for all the three distribution are given in Table 2. We obtain the optimal cycle time as $T=0.64$ years (for uniform distribution), $T=0.66$ years (for triangular distribution) and $T=0.67$ years (for beta distribution). The optimal container capacity is $\lambda=3$ units (for uniform distribution), $\lambda=4$ units (for triangular distribution) and $\lambda=5$ units (for beta distribution). For optimal remanufacturing rate, the results are $\tau=65$ percent (for uniform distribution), $\tau=69$ percent (for triangular distribution) and $\tau=73$ percent (for beta distribution). The optimal prices are $p=\$ 581.21$ (for uniform distribution), $p=\$ 582.6$ (for triangular distribution) and $p=\$ 581.4$ (for beta distribution). From the total profit, it is clear that the highest profit is yielded by uniform distribution $\$ 828,278$ followed by the beta distribution $\$ 827,970$. The least profit is obtained from triangular distribution, which is $\$ 824,728$.

Table 2. Optimal results of three examples.

\begin{tabular}{lccc}
\hline & Example 1 & Example 2 & Example 3 \\
\hline Distribution of Defective Rate & Uniform & Triangular & beta \\
\hline$\Pi(\$)$ & 828,278 & 824,728 & 827,970 \\
$T^{*}($ days $)$ & 0.634 & 0.66 & 0.67 \\
$\lambda^{*}($ units $)$ & 3 & 4 & 5 \\
$\tau^{*}(\%)$ & 0.65 & 0.69 & 0.73 \\
$P^{*}(\$)$ & 581.21 & 582.64 & 581.43 \\
\hline
\end{tabular}

\subsection{Sensitivity Analysis}

A sensitivity analysis is performed for all the key parameters and the results are compiled in Tables 3-8. Table 3 provides sensitivity analysis of key parameters related to manufacture and 3PL. From the results, the following insights are obtained:

- The most influential parameter for all the three examples is manufacturing cost. Decreasing the manufacturing cost increases the profit of the system. However, the percentage change in 
profit to both positive and negative changes in manufacturing cost is asymmetric. Decreasing manufacturing cost by 50 percent increases the total profit by around $11 \%$, on the other hand, an equal increase reduces the profit by less than one percent. Thus, it can be concluded that the profit is more sensitive to negative changes in manufacturing cost compared to the positive changes. Hence, in hybrid systems, supply chain managers must focus on technologies to reduce manufacturing cost to improve overall profitability.

- Almost similar results are shown by remanufacturing cost. Decreasing remanufacturing cost by $50 \%$ increases profit by more than $8 \%$ for all examples, while increasing remanufacturing cost by $50 \%$ reduces profit by less than one percent.

- In the case of investment for the collection of used product, the models showed opposite asymmetry. In this case, the profit is more sensitive towards positive changes in the investment cost. A $50 \%$ increase in investment cost reduces total profit by $0.37 \%$ and a $50 \%$ decrease only increases the profit by $0.16 \%$. Hence it can be concluded that the sensitivity of profit towards positive change is almost double of the negative change.

- An interesting result is obtained from the sensitivity of production rate. The results are different for different examples. For beta distribution, the percent change is almost symmetric in both directions. For uniform distribution, the results are less asymmetric, however, for triangular distribution, the results show a higher degree of asymmetry compared to the other two models. This shows that for supply chains, in which the defective rate follows a triangular distribution, increasing the production rate will not increase the profit. However, in the case of uniform and beta, distribution production rate can be used as a tool to increase the profit of the supply chain.

- Among the three examples, the model with triangular distribution is more sensitive towards manufacturer's setup cost compared to uniform and beta distributions. This means that for supply chain systems, where the defective rate follows a triangular distribution, managers must focus on reduction of the manufacturer's setup cost.

Table 3. Sensitivity analysis for parameters related to manufacturer and 3PL.

\begin{tabular}{ccccc}
\hline Parameter & \% Change in & \% Change in $\Pi$ & \% Change in $\Pi$ & \% Change in $\Pi$ \\
\hline \multirow{2}{*}{$C_{m}$} & Value & (Uniform) & \% (Triangular) & (beta) \\
& $-50 \%$ & 11.19 & 11.28 & 11.19 \\
& $-25 \%$ & 5.45 & 5.472 & 5.43 \\
& $+25 \%$ & -0.086 & -0.106 & -0.08 \\
$C_{r}$ & $+50 \%$ & -0.123 & -0.138 & -0.14 \\
& $-50 \%$ & 8.603 & 8.625 & 8.582 \\
& $-25 \%$ & 4.254 & 4.259 & 4.256 \\
& $+25 \%$ & -0.159 & -0.17 & -0.151 \\
$\gamma$ & $+50 \%$ & -0.163 & -0.17 & -0.163 \\
& $-50 \%$ & 0.169 & 0.138 & 0.13 \\
& $-25 \%$ & 0.065 & 0.0591 & 0.07 \\
$P_{m}$ & $+25 \%$ & -0.033 & -0.043 & -0.03 \\
& $+50 \%$ & -0.374 & -0.13 & -0.37 \\
& $-50 \%$ & -0.037 & -0.035 & -0.031 \\
& $-25 \%$ & 0.001 & -0.012 & 0.001 \\
$S_{m}$ & $+25 \%$ & 0.022 & 0.001 & 0.022 \\
& $+50 \%$ & 0.028 & 0.013 & 0.028 \\
& $-50 \%$ & 0.019 & 0.004 & 0.019 \\
& $-25 \%$ & 0.017 & 0.0026 & 0.002 \\
& $+25 \%$ & 0.001 & -0.002 & 0.001 \\
& $+50 \%$ & 0.009 & -0.106 & -0.008 \\
\hline
\end{tabular}

Sensitivity of all other parameters, related to manufacturer and 3PL, is given in Table A1, Appendix C. 
This paper assumed that the demand depends upon price and investment in $\mathrm{O} 2 \mathrm{O}$ channel that attracts more customers. Table 4 provides a sensitivity analysis of the demand parameters $b$ and $k$. The following insights are obtained from the results:

- $\quad$ The profit of the system increases with a decrease in the demand parameter $b$, and decreases with a decrease in $k$. However, the percent change is different for both the parameters.

- Considering the demand parameter $b$, a 50\% decrease produces a $114.8 \%$ increase for both uniform and beta distributions. The increase for the triangular distribution is, however, slightly higher, $115.3 \%$. Similarly, on the positive side, triangular distribution is also slightly more sensitive compared to the beta distribution and uniform distribution.

- In the case of demand parameter $k$, the triangular distribution shows a $21.03 \%$ decrease to $50 \%$ decrease in $k$, which is slightly higher than beta distribution, $20.92 \%$, and uniform distribution, $20.90 \%$. On the positive side, however, the results are comparable with slight differences. For a $50 \%$ increase in $k$, the total profit increased by $23.3 \%$ for the uniform distribution, $23.48 \%$ for the triangular distribution, and $23.38 \%$ for the beta distribution.

Table 4. Sensitivity analysis for demand parameters.

\begin{tabular}{ccccc}
\hline Parameter & \% Change in & \% Change in $\Pi$ & $\%$ Change in $\Pi$ & \% Change in $\Pi$ \\
\hline & Value & (Uniform) & \% (Triangular) & (beta) \\
\hline $\mathrm{b}$ & $-50 \%$ & 114.8 & 115.3 & 114.8 \\
& $-25 \%$ & 38.2 & 38.59 & 38.26 \\
& $+25 \%$ & -22.7 & -23.46 & -22.87 \\
$\mathrm{k}$ & $+50 \%$ & -38.09 & -38.46 & -38.19 \\
& $-50 \%$ & -20.90 & -21.03 & -20.92 \\
& $-25 \%$ & -10.7 & -10.81 & -10.76 \\
& $+25 \%$ & 11.38 & 11.42 & 11.40 \\
& $+50 \%$ & 23.3 & 23.48 & 23.38 \\
\hline
\end{tabular}

This paper assumes random defective rates. It is a common assumption in the traditional modeling approaches, that higher defective rates generate low profits. However, this is not the case for this paper. Traditional modeling approaches either considered rework or scrap option for defective products. However, our modeling approach considered that defective products are salvaged. Now two situations arise: (1) salvage value of the defective product is more than the outsourcing cost, (2) salvage value of defective products is less than the outsourcing cost. In the first case, the generated revenue is more than cost and hence decreasing the defective rate decreases the total profit. While in the second case, the generated revenue from defective products is less than the total production cost, hence, the total profit increases with the decrease in defective rate.

\subsubsection{Case 2}

To investigate this phenomenon in detail, we consider a second numerical example. All parametric values are taken from example 1, except that salvage value $c w$ is considered less than the outsourcing cost of the products. In this particular case, we considered $c w=100<o w=115$. The results of case 2 are compiled in Table 5. The results show that the profit of the supply chain is reduced; however, this is obvious as the revenue from defective product salvaging is reduced by $50 \%$. Among the three different distributions, the highest profit is generated by triangular distribution compared to the previous case, in which triangular distribution generated the lowest profit. 
Table 5. Optimal results of three examples, Case 2.

\begin{tabular}{lccc}
\hline & Example & Example 2 & Example 3 \\
\hline Distribution of Defective Rate & Uniform & Triangular & beta \\
\hline$\Pi(\$)$ & 781,267 & 781,911 & 781,326 \\
$T^{*}($ days $)$ & 0.681203 & 0.681946 & 0.681272 \\
$\lambda^{*}($ units $)$ & 5 & 5 & 5 \\
$\tau^{*}(\%)$ & 0.712269 & 0.710318 & 0.712085 \\
$P^{*}(\$)$ & 594.779 & 594.59 & 594.762 \\
\hline
\end{tabular}

In order to clearly understand the relationship of salvage value, defective percentage, and profit of the system, a sensitivity analysis for defective rate parameters is performed for both the examples. The results of sensitivity are summarized in Tables 6 and 7. The results very clearly show that the sensitivity of profit is reversed for the second case. Although the negative and positive changes in the defective rate result in asymmetric changes in the total profit, the trend remains the same. The following important insights can be drawn from the sensitivity analysis:

- For the uniform distribution, increasing the parameter $x$ increases the profit of the system under Case 1 and decreases it under Case 2. Increasing the distribution parameter $x$ increases the expected value of the defective rate, this means, increasing the defective rate increases the profit of the system in Case 1 and decreases the profit in Case 2. The results are also similar for triangular distribution, in which the expected value increases with increasing the parameter $x$. However, $x$ is more effective in uniform distribution compared to triangular distribution, this is because the net effect in the expected value is more in uniform distribution compared to triangular distribution.

- Increasing the parameter $y$ also increases the expected value of the defective rate. Therefore, increasing the parameter $y$ increases the profit of the system under Case 1 and decreases profit under Case 2, for both uniform and triangular distributions. The impact of $y$ is more than double compared to the impact of $x$ for uniform distribution; for triangular distribution, the impact of $x$, on profit, is about $50 \%$ the effect of $y$.

- The parameter $z$ only applies to the triangular distribution, therefore, it has no effect on uniform distribution. For triangular distribution, increasing $z$ increases the profit of Case 1 and decreases the profit of Case 2.

- For beta distribution, increasing $\lambda$ increases the expected value of the defective rate, therefore, it increases the profit in Case 1 and decreases it in Case 2. On the other hand, increasing $\beta$ decreases the expected value of the defective rate and, therefore, when $\beta$ is increased, the profit of Case 1 is reduced and the profit of Case 2 is increased.

From the above results it is clear that, for Case 1, total profit increases with an increase in the defective rate, while for Case 2, the total profit decreases with an increase in the defective rate. The cost of outsourcing can also be considered as the cost of shortage and lost sales. Whatever be the situation or assumptions, if the cost is more than salvage value, supply chain managers need not worry about the defective rate. However, when the cost of shortage, outsourcing, or lost sales is more than the salvage value of imperfect items, supply chain managers should focus on reduction of defective rate. 
Table 6. Sensitivity analysis for parameter related to defective rate (uniform and triangular distributions).

\begin{tabular}{cccccc}
\hline Parameter & \multicolumn{2}{c}{ Case 1, cw $>$ ow } & \multicolumn{2}{c}{ Case 2, cw $<$ ow } \\
\hline in Value & $\begin{array}{c}\text { \% Change in } \Pi \\
\text { (Uniform) }\end{array}$ & $\begin{array}{c}\text { \% Change in } \Pi \\
\text { (Triangular) }\end{array}$ & $\begin{array}{c}\text { \% Change in } \Pi \\
\text { (Uniform) }\end{array}$ & $\begin{array}{c}\text { \% Change in } \Pi \\
\text { (Triangular) }\end{array}$ \\
\hline$x$ & $-50 \%$ & -0.65 & -0.44 & 0.13 & 0.09 \\
& $-25 \%$ & -0.32 & -0.22 & 0.001 & 0.05 \\
$+25 \%$ & 0.33 & 0.21 & -0.06 & -0.04 \\
& $+50 \%$ & 0.67 & 0.44 & -0.14 & -0.08 \\
$y$ & $-50 \%$ & -1.76 & -0.60 & 0.34 & 0.23 \\
& $-25 \%$ & -0.88 & -0.29 & 0.16 & 0.12 \\
& $+25 \%$ & 0.88 & 0.59 & -0.16 & -0.10 \\
& $+50 \%$ & 1.77 & 1.15 & -0.35 & -0.21 \\
& $-50 \%$ & 0.00 & -1.35 & 0.00 & 0.12 \\
& $-25 \%$ & 0.00 & -0.67 & 0.00 & 0.06 \\
& $+25 \%$ & 0.00 & 0.29 & 0.00 & -0.05 \\
& $+50 \%$ & 0.00 & 0.59 & 0.00 & -0.10 \\
\hline
\end{tabular}

Table 7. Sensitivity analysis for parameter related to defective rate (beta distribution).

\begin{tabular}{cccc}
\hline & & Case 1, cw $>$ ow & Case 2, cw < ow \\
\hline Parameter & $\%$ Changes in Value & $\%$ Change in $\Pi$ (beta) & $\%$ Change in $\Pi$ (beta) \\
\hline$\lambda$ & $-50 \%$ & -2.04 & 0.39 \\
& $-25 \%$ & -0.95 & 0.18 \\
& $+25 \%$ & 0.78 & -0.15 \\
& $+50 \%$ & 1.40 & -0.29 \\
$\beta$ & $-50 \%$ & 2.78 & -0.54 \\
& $-25 \%$ & 1.04 & -0.18 \\
& $+25 \%$ & -0.74 & 0.15 \\
& $+50 \%$ & -1.30 & 0.25 \\
\hline
\end{tabular}

Finally, we considered the impacts of investment cost in the $\mathrm{O} 2 \mathrm{O}$ channel on total profit. Sensitivity analysis is performed for information cost and transportation cost. The results are compiled in Table 8 . The results clearly show that rise in investment cost increases total profit. The effect is slightly asymmetric; the profit is more sensitive towards positive changes compared to negative changes.

Table 8. Sensitivity analysis of $\mathrm{O} 2 \mathrm{O}$ channel parameters.

\begin{tabular}{lcccc}
\hline Parameter & $\begin{array}{c}\text { \% Change in } \\
\text { Value }\end{array}$ & $\begin{array}{c}\text { \% Change in } \Pi \\
\text { (Uniform) }\end{array}$ & $\begin{array}{c}\text { \% Change in } \Pi \\
\text { \% (Triangular) }\end{array}$ & $\begin{array}{c}\text { \% Change in } \Pi \\
\text { (beta) }\end{array}$ \\
\hline $\mathrm{IN}_{i}$ & $-50 \%$ & -20.76 & -20.83 & -20.7 \\
& $-25 \%$ & -10.67 & -10.72 & -10.6 \\
& $+25 \%$ & 11.293 & 11.34 & 11.29 \\
$\mathrm{TR}_{i}$ & $+50 \%$ & 23.142 & 23.27 & 23.15 \\
& $-50 \%$ & 0.080 & 0.091 & 0.080 \\
& $-25 \%$ & 0.064 & -0.016 & 0.064 \\
& $+25 \%$ & -0.043 & -0.058 & -0.04 \\
& $+50 \%$ & -0.090 & -0.096 & -0.09 \\
\hline
\end{tabular}

\section{Conclusions}

This paper studies joint pricing and inventory policies for a multi-echelon CLSC model with an $\mathrm{O} 2 \mathrm{O}$ sales channel. In order to reduce solid waste generation in supply chain, RTI is used to transport finished products from the manufacturer to retailers. A 3PL collects used products from the consumer and delivers them to the manufacturer for remanufacturing. Furthermore, carbon emissions from transportation and production activities are also considered to improve the environmental performance 
of supply chain management. Imperfect production is investigated with a random defective rate, whereas the defective rate follows three different probability distributions. Traditionally, supply chain inventory management considered rework or scrap option for the defective product. However, this model considered that defective products are salvaged, which generated extra revenue. Based on this assumption, two cases were developed, and the results showed that unlike traditional modeling approaches, total profit increases with an increase in defective rate when the salvage value of defective products is more than the cost of outsourcing. When the cost of outsourcing is higher compared to the salvage value, our model converged to traditional modeling approaches, in which profit decreases with an increase in defective rate. The results further showed that in CLSC models the most important parameters are manufacturing cost and remanufacturing cost, their decrease produces more positive impacts compared to the negative impacts caused by their increments. Moreover, the sensitivity analysis provided that investment in the $\mathrm{O} 2 \mathrm{O}$ channel leads to a substantial increase in total profit. This research can be extended in many directions, for example, as we considered deterministic demand, considerations of stochastic demand would be a more realistic example. Furthermore, the modeling approach of defective items needs to be explored further in the presences of shortage cots, lost sales and back ordering. Another important extension of this model is to consider deteriorated products, such as the study done by Ullah et al. [63].

Author Contributions: Conceptualization, B.S. and M.U.; Methodology, B.S. and M.U.; Software, M.U.; Validation, B.S.; Formal analysis, B.S. and M.U.; Investigation, B.S. and M.U.; Resources, B.S. and M.U.; Data curation, B.S. and M.U.; Writing—original draft preparation, M.U.; Writing—review and editing, M.U.; Visualization, B.S. and M.U.; Supervision, B.S. and S.-B.C.

Funding: This research received no external funding.

Conflicts of Interest: The authors declare no conflict of interest.

\section{Abbreviations}

The following notation are used to develop mathematical model.

\section{Notation}

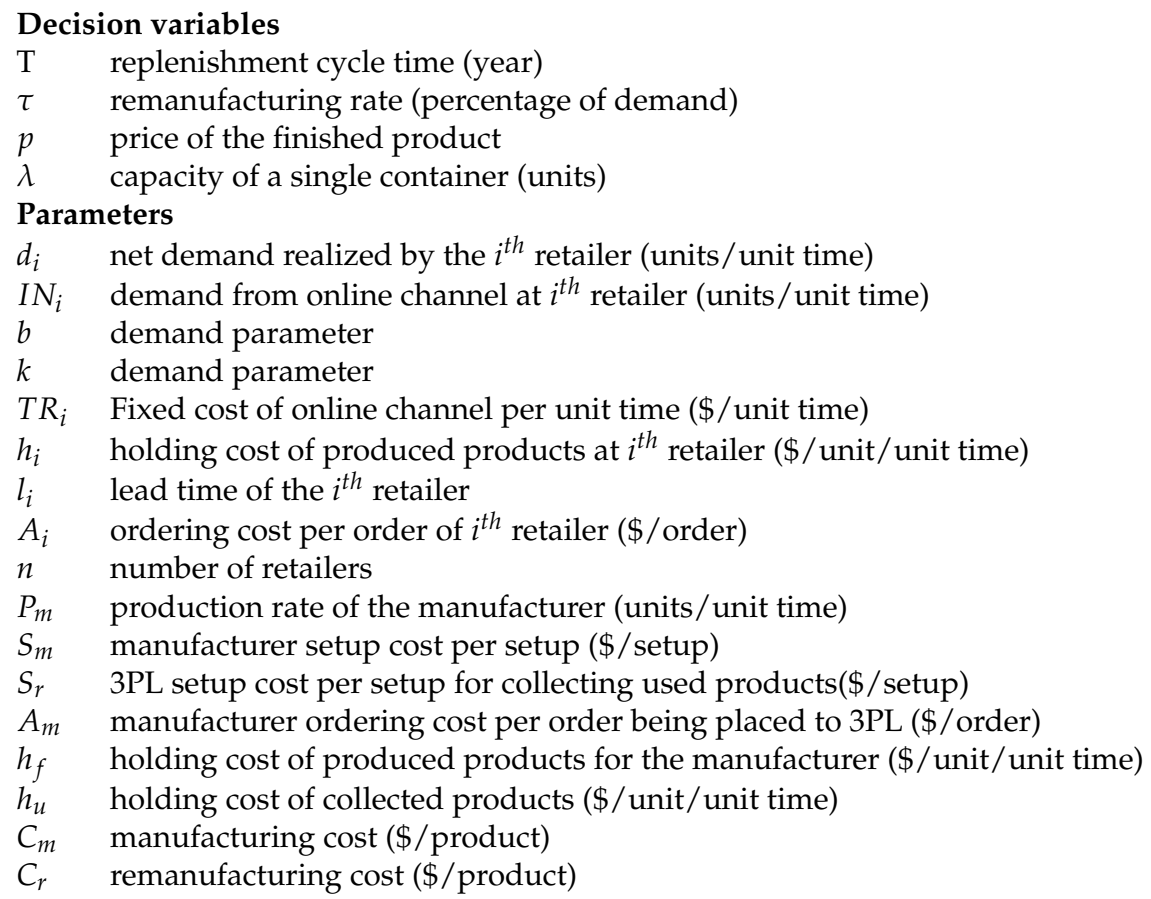


$C_{q} \quad$ quality improving cost (\$/product)

$g$ goodwill lost cost for the manufacturer (\$/product)

$A_{t} \quad$ average incentives paid to consumer for collected products (\$/unit)

$C_{t} \quad$ transportation cost per container per unit distance (\$/container/unit distance)

$l_{\text {im }} \quad$ distance between the manufacturer and retailer $i$ (kilometers)

$l_{i j} \quad$ distance between retailer $i$ and 3PL (kilometers)

$l_{j m} \quad$ distance between 3PL and the manufacturer (kilometers)

$C_{\lambda} \quad$ cost of managing RTIs, including depreciation and repair per unit capacity of RTI (\$/RTI capacity)

$S \quad$ scaling factor for how the container capacity affects the cost of managing a container

$h_{R} \quad$ holding cost of containers at 3PL (\$/unit/unit time)

$\gamma \quad$ effective investment by 3PL to collects EOL/EOU products in dollars (\$)

$e_{m} \quad$ carbon emissions per product from manufacturing ( $\mathrm{kg} /$ product)

$e_{r} \quad$ carbon emissions per gallon of fuel used by truck ( $\mathrm{kg} /$ gallon)

$g_{m} \quad$ fuel required per mile (gallon/miles)

$\mathrm{C}_{\mathrm{ec}} \quad$ carbon tax per unit of emitted carbon (\$/unit of emitted carbon)

$C_{q} \quad$ quality upgradation cost $(\$ /$ product $)$

$t_{c} \quad$ truck capacity (number of products)

cw salvage value of defective products (\$/unit)

ow cost of out sourcing one product (\$/unit), ow $>C_{m}$

ck inspection cost per product (\$/unit)

$r$ defective rate (random variable)

$T C_{1} \quad$ cost of multiple retailers $(\$ /$ cycle $)$

$T C_{2}$ cost of manufacturer (\$/cycle)

$T C_{3}$ cost of $3 \mathrm{PL}(\$ /$ cycle $)$

The following abbreviations are used in this manuscript.

$\mathrm{O} 2 \mathrm{O}$ Online to offline

CLSC Closed-loop supply chain

RTI Returnable transport item

3PL Third party logistics

\section{Appendix A}

Appendix A.1

From Figure 2, manufacturer inventory can be written as,

$$
\begin{gathered}
\frac{Q^{2}}{2(1-r) P_{m}}+l_{1}\left(Q-q_{1}\right)+l_{2}\left(Q-q_{1}-q_{2}\right) \ldots \ldots \ldots+l_{n-1}\left(Q-q_{1}-q_{2} \ldots \ldots . . .-q_{n-1}\right) \\
Q=\left(q_{1}+q_{2}+q_{3}+q_{4} \ldots\right) \cdot\left(+q_{n-1}\right)+q_{n} \\
\frac{Q^{2}}{2(1-r) P_{m}}+T \sum_{i=1}^{n-1} l_{i} d_{i}
\end{gathered}
$$

Therefore, the time-weighted average inventory is

$$
\frac{d^{2} T}{2(1-r) P_{m}}+\sum_{i=1}^{n-1} l_{i} d_{i+1}
$$


Appendix A.2

The average inventory of RTI at 3PL can be calculated with the help of Figure 2.

$$
\begin{aligned}
& =r_{\max }\left(T-\sum_{i=1}^{n} l_{i}\right)+\sum_{i=1}^{n} l_{i}\left(r_{\max }-r_{i}\right) \\
& =\frac{d_{\max } T}{\lambda}\left(T-\sum_{i=1}^{n} l_{i}\right)+\sum_{i=1}^{n} l_{i}\left(\frac{d_{\max } T}{\lambda}-\frac{T}{\lambda} d_{i}\right) .
\end{aligned}
$$

Therefore, the time weighted average inventory of RTI at 3PL

$$
=\frac{d_{\max }}{\lambda}\left(T-\sum_{i=1}^{n} l_{i}\right)+\sum_{i=1}^{n} l_{i}\left(\frac{d_{\max }}{\lambda}-\frac{1}{\lambda} d_{i}\right) \text {. }
$$

\section{Appendix B}

If,

$a_{1,1}=\frac{\partial}{\partial T} \frac{\partial \Pi}{\partial T}, a_{1,2}=\frac{\partial}{\partial \tau} \frac{\partial \Pi}{\partial T}, a_{1,3}=\frac{\partial}{\partial \lambda} \frac{\partial \Pi}{\partial T}, a_{1,4}=\frac{\partial}{\partial p} \frac{\partial \Pi}{\partial T}, a_{2,1}=\frac{\partial}{\partial T} \frac{\partial \Pi}{\partial \tau}, a_{2,2}=\frac{\partial}{\partial \tau} \frac{\partial \Pi}{\partial \tau}, a_{2,3}=\frac{\partial}{\partial \lambda} \frac{\partial \Pi}{\partial \tau}, a_{2,4}=$ $\frac{\partial}{\partial p} \frac{\partial \Pi}{\partial \tau}, a_{3,1}=\frac{\partial}{\partial T} \frac{\partial \Pi}{\partial \lambda}, a_{3,2}=\frac{\partial}{\partial \tau} \frac{\partial \Pi}{\partial \lambda}, a_{3,3}=\frac{\partial}{\partial \lambda} \frac{\partial \Pi}{\partial \lambda}, a_{3,4}=\frac{\partial}{\partial p} \frac{\partial \Pi}{\partial \lambda}, a_{4,1}=\frac{\partial}{\partial T} \frac{\partial \Pi}{\partial p}, a_{4,2}=\frac{\partial}{\partial \tau} \frac{\partial \Pi}{\partial p}, a_{4,3}=$ $\frac{\partial}{\partial \lambda} \frac{\partial \Pi}{\partial p}, a_{4,4}=\frac{\partial}{\partial p} \frac{\partial \Pi}{\partial p}$

Then the Hessian matrix of (5) can be expressed as

$$
H=\left(\begin{array}{llll}
a_{1,1} & a_{1,2} & a_{1,3} & a_{1,4} \\
a_{2,1} & a_{2,2} & a_{2,3} & a_{2,4} \\
a_{3,1} & a_{3,2} & a_{3,3} & a_{3,4} \\
a_{4,1} & a_{4,2} & a_{4,3} & a_{4,4}
\end{array}\right)
$$

Appendix B.1. When Defective Rate Follows Uniform Distribution

The Hessian matrix for example 1 , when defective rate follows uniform distribution, at $T=0.634$; $\lambda=3 ; \tau=0.65 ; p=581.21$ is,

$$
\left(\begin{array}{cccc}
-33524.3 & 4001.85 & 487.243 & 23.4258 \\
4001.85 & -6199.8 & 300.356 & -9.77975 \\
487.243 & 300.356 & -503.327 & -0.693627 \\
23.4258 & -9.77975 & -0.693627 & -7.20307
\end{array}\right)
$$

The first four principle minors are $-33524.3,+1.91829 \times 10^{8},-9.08852 \times 10^{10}$, and $+6.5227 \times 10^{11}$. Hence total profit is strictly concave at $T=0.634 ; \lambda=3 ; \tau=0.65 ; p=581.21$.

Appendix B.2. When Defective Rate Follows Triangular Distribution

The Hessian matrix for example 2, when defective rate follows triangular distribution, at $T=0.66$; $\lambda=4 ; \tau=0.69 ; p=582.64$ is,

$$
\left(\begin{array}{cccc}
-31987.9 & 4059.47 & 273.633 & 23.041 \\
4059.47 & -6060.61 & 168.46 & -10.0465 \\
273.633 & 168.46 & -216.887 & -0.208652 \\
23.041 & -10.0465 & -0.208652 & -7.20295
\end{array}\right)
$$

The first four principle minors are $-31987.9,+1.77387 \times 10^{8},-3.6737 \times 10^{10}$, and $+2.63656 \times 10^{11}$. Hence total profit is strictly concave at $T=0.66 ; \lambda=4 ; \tau=0.69 ; p=582.64$. 
Appendix B.3. When Defective Rate Follows Beta Distribution

The Hessian matrix for example 3, when defective rate follows beta distribution, at $T=0.67 ; \lambda=5$; $\tau=0.73 ; p=581.43$ is,

$$
\left(\begin{array}{cccc}
-31332.3 & 4222.72 & 175.343 & 23.1492 \\
4222.72 & -5970.15 & 108.056 & -10.3247 \\
175.343 & 108.056 & -113.68 & 0.0186797 \\
23.1492 & -10.3247 & 0.0186797 & -7.20296
\end{array}\right)
$$

The first four principle minors are $-31332.3,+1.69227 \times 10^{8},-1.85284 \times 10^{10}$, and $+1.32964 \times 10^{11}$. Hence total profit is strictly concave at $T=0.67 ; \lambda=5 ; \tau=0.73 ; p=581.43$.

\section{Appendix C.}

Table A1. Sensitivity analysis for parameters related to manufacturer and 3PL.

\begin{tabular}{|c|c|c|c|c|}
\hline Parameter & $\begin{array}{c}\% \text { Change in } \\
\text { Value }\end{array}$ & $\begin{array}{c}\% \text { Change in } \Pi \\
\text { (Uniform) }\end{array}$ & $\begin{array}{l}\% \text { Change in } \Pi \\
\% \text { (Triangular) }\end{array}$ & $\begin{array}{c}\% \text { Change in } \Pi \\
\text { (beta) }\end{array}$ \\
\hline \multirow[t]{4}{*}{$h_{f}$} & $-50 \%$ & 0.059 & 0.010 & 0.059 \\
\hline & $-25 \%$ & 0.037 & 0.0211 & 0.003 \\
\hline & $+25 \%$ & -0.006 & -0.027 & -0.007 \\
\hline & $+50 \%$ & -0.029 & -0.049 & -79.6 \\
\hline \multirow[t]{4}{*}{$h_{u}$} & $-50 \%$ & 0.302 & 0.290 & 0.302 \\
\hline & $-25 \%$ & 0.143 & 0.133 & 0.147 \\
\hline & $+25 \%$ & -0.09 & -0.091 & -0.091 \\
\hline & $+50 \%$ & -0.15 & -0.196 & -0.152 \\
\hline \multirow[t]{4}{*}{$A_{m}$} & $-50 \%$ & 0.001 & 0.0017 & 0.001 \\
\hline & $-25 \%$ & 0.008 & 0.0008 & 0.0002 \\
\hline & $+25 \%$ & -0.008 & -0.0008 & 0.013 \\
\hline & $+50 \%$ & 0.012 & -0.001 & 0.002 \\
\hline \multirow[t]{4}{*}{$C_{t}$} & $-50 \%$ & 0.039 & 0.064 & 0.039 \\
\hline & $-25 \%$ & 0.044 & 0.030 & 0.028 \\
\hline & $+25 \%$ & -0.02 & -0.034 & -0.020 \\
\hline & $+50 \%$ & -0.04 & -0.057 & -0.044 \\
\hline \multirow[t]{4}{*}{$A_{t}$} & $-50 \%$ & 2.011 & 1.999 & 2.01 \\
\hline & $-25 \%$ & 0.999 & 0.989 & 1.00 \\
\hline & $+25 \%$ & -0.1596 & -0.17 & -0.20 \\
\hline & $+50 \%$ & -0.186 & -0.17 & -0.16 \\
\hline \multirow[t]{4}{*}{$C_{\lambda}$} & $-50 \%$ & 0.131 & 0.101 & 0.115 \\
\hline & $-25 \%$ & 0.06 & 0.04 & 0.064 \\
\hline & $+25 \%$ & -0.03 & -0.05 & -0.030 \\
\hline & $+50 \%$ & -0.086 & -0.09 & -0.075 \\
\hline \multirow[t]{4}{*}{$C_{q}$} & $-50 \%$ & 0.381 & 0.345 & 0.381 \\
\hline & $-25 \%$ & 0.203 & 0.179 & 0.192 \\
\hline & $+25 \%$ & -0.18 & -0.182 & -0.19 \\
\hline & $+50 \%$ & -0.37 & -0.40 & -0.375 \\
\hline \multirow[t]{4}{*}{$q_{r}$} & $-50 \%$ & -0.03 & -0.045 & -0.033 \\
\hline & $-25 \%$ & -0.02 & -0.021 & -0.028 \\
\hline & $+25 \%$ & 0.044 & 0.030 & 0.0446 \\
\hline & $+50 \%$ & 0.10 & 0.085 & 0.100 \\
\hline \multirow[t]{4}{*}{ ck } & $-50 \%$ & 0.522 & 0.510 & 0.507 \\
\hline & $-25 \%$ & 0.253 & 0.2548 & 0.253 \\
\hline & $+25 \%$ & -0.256 & -0.254 & -0.25 \\
\hline & $+50 \%$ & -0.506 & -0.508 & -0.50 \\
\hline \multirow[t]{4}{*}{$h_{R}$} & $-50 \%$ & 0.0078 & 0.04 & 0.007 \\
\hline & $-25 \%$ & 0.0256 & -0.024 & 0.02 \\
\hline & $+25 \%$ & -0.049 & -0.033 & -0.02 \\
\hline & $+50 \%$ & -0.098 & -0.089 & -0.02 \\
\hline
\end{tabular}




\section{References}

1. Cassab, H.; MacLachlan, D.L. Interaction fluency: A customer performance measure of multichannel service. Int. J. Prod. Perform. Manag. 2006, 55, 555-568. [CrossRef]

2. Yang, S.; Lu, Y.; Chau, P.Y. Why do consumers adopt online channel? An empirical investigation of two channel extension mechanisms. Decis. Support Syst. 2013, 54, 858-869. [CrossRef]

3. Chang, Y.W.; Hsu, P.Y.; Yang, Q.M. Integration of online and offline channels: A view of O2O commerce. Internet Res. 2018, 28, 926-945. [CrossRef]

4. Sarkar, B.; Tayyab, M.; Choi, S.B. Product Channeling in an O2O Supply Chain Management as Power Transmission in Electric Power Distribution Systems. Mathematics 2019, 7, 4. [CrossRef]

5. Livne, G.; Simpson, A.; Talmor, E. Do customer acquisition cost, retention and usage matter to firm performance and valuation? J. Bus. Financ. Account. 2011, 38, 334-363. [CrossRef]

6. Sarkar, B.; Ullah, M.; Kim, N. Environmental and economic assessment of closed-loop supply chain with remanufacturing and returnable transport items. Comput. Ind. Eng. 2017, 111, 148-163. [CrossRef]

7. Bulmus, S.C.; Zhu, S.X.; Teunter, R. Competition for cores in remanufacturing. Eur. J. Oper. Res. 2014, 233, 105-113. [CrossRef]

8. Taleizadeh, A.A.; Sane-Zerang, E.; Choi, T.M. The effect of marketing effort on dual-channel closed-loop supply chain systems. IEEE Trans. Syst. Man Cybern. Syst. 2018, 48, 265-276. [CrossRef]

9. Schrady, D.A. A deterministic inventory model for reparable items. Nav. Res. Logist. 1967, 14, $391-398$. [CrossRef]

10. Richter, K. The EOQ repair and waste disposal model with variable setup numbers. Eur. J. Oper. Res. 1996, 95, 313-324. [CrossRef]

11. Richter, K. The extended EOQ repair and waste disposal model. Int. J. Prod. Econ. 1996b, 45, $443-447$. [CrossRef]

12. Richter, K. Pure and mixed strategies for the EOQ repair and waste disposal problem. Oper. Res. Spekt. 1997, 19, 123-129. [CrossRef]

13. Richter, K.; Dobos, I. Analysis of the EOQ repair and waste disposal problem with integer setup numbers. Int. J. Prod. Econ. 1999, 59, 463-467. [CrossRef]

14. Dobos, I.; Richter, K. An extended production/recycling model with stationary demand and return rates. Int. J. Prod. Econ. 2004, 90, 311-323. [CrossRef]

15. Dobos, I.; Richter, K. A production/recycling model with quality consideration. Int. J. Prod. Econ. 2006, 104, 571-579. [CrossRef]

16. Maiti, T.; Giri, B. A closed loop supply chain under retail price and product quality dependent demand. J. Manuf. Syst. 2015, 37, 624-637. [CrossRef]

17. Moshtagh, M.S.; Taleizadeh, A.A. Stochastic integrated manufacturing and remanufacturing model with shortage, rework and quality based return rate in a closed loop supply chain. J. Clean. Prod. 2017, 141, 1548-1573. [CrossRef]

18. Tian, X.; Zhang, Z.H. Capacitated disassembly scheduling and pricing of returned products with price-dependent yield. Omega 2019, 84, 160-174. [CrossRef]

19. Govindan, K.; Soleimani, H. A review of reverse logistics and closed-loop supply chains: A Journal of Cleaner Production focus. J. Clean. Prod. 2017, 142, 371-384. [CrossRef]

20. Diallo, C.; Venkatadri, U.; Khatab, A.; Bhakthavatchalam, S. State of the art review of quality, reliability and maintenance issues in closed-loop supply chains with remanufacturing. Int. J. Prod. Res. 2017, 55, 1277-1296. [CrossRef]

21. Chiang, W.Y.K.; Chhajed, D.; Hess, J.D. Direct marketing, indirect profits: A strategic analysis of dual-channel supply-chain design. Manag. Sci. 2003, 49, 1-20. [CrossRef]

22. Huang, S.; Yang, C.; Zhang, X. Pricing and production decisions in dual-channel supply chains with demand disruptions. Comput. Ind. Eng. 2012, 62, 70-83. [CrossRef]

23. Ahmad, W.; Sarkar, B.; Ullah, M. Impact of Reparation for Imperfect Quality Items having Shortages in the System under Multi-Trade-Credit-Period. DJ J. Eng. Appl. Math. 2018, 5, 1-16. [CrossRef]

24. Tsay, A.A.; Agrawal, N. Channel conflict and coordination in the e-commerce age. Prod. Oper. Manag. 2004, 13, 93-110. [CrossRef] 
25. Yao, D.Q.; Liu, J.J. Competitive pricing of mixed retail and e-tail distribution channels. Omega 2005, 33, 235-247. [CrossRef]

26. Huang, W.; Swaminathan, J.M. Introduction of a second channel: Implications for pricing and profits. Eur. J. Oper. Res. 2009, 194, 258-279. [CrossRef]

27. Yan, R. Pricing strategy for companies with mixed online and traditional retailing distribution markets. J. Prod. Brand Manag. 2008, 17, 48-56. [CrossRef]

28. Dan, B.; Xu, G.; Liu, C. Pricing policies in a dual-channel supply chain with retail services. Int. J. Prod. Econ. 2012, 139, 312-320. [CrossRef]

29. Li, B.; Zhu, M.; Jiang, Y.; Li, Z. Pricing policies of a competitive dual-channel green supply chain. J. Clean. Prod. 2016, 112, 2029-2042. [CrossRef]

30. Bányai, T.; Illés, B.; Bányai, Á. Smart scheduling: An integrated first mile and last mile supply approach. Complexity 2018, 2018, 5180156 [CrossRef]

31. Bányai, T. Real-time decision making in first mile and last mile logistics: How smart scheduling affects energy efficiency of hyperconnected supply chain solutions. Energies 2018, 11, 1833. [CrossRef]

32. Habib, M.S.; Sarkar, B.; Tayyab, M.; Saleem, M.W.; Hussain, A.; Ullah, M.; Omair, M.; Iqbal, M.W. Large-scale disaster waste management under uncertain environment. J. Clean. Prod. 2019, 212, 200-222. [CrossRef]

33. Ullah, M.; Sarkar, B. Smart and sustainable supply chain management: A proposal to use rfid to improve electronic waste management. In Proceedings of the International Conference on Computers and Industrial Engineering, Auckland, New Zealand, 2-5 December 2018; Volume 2018.

34. Johansson, O.; Hellström, D. The effect of asset visibility on managing returnable transport items. Int. J. Phys. Distrib. Logist. Manag. 2007, 37, 799-815. [CrossRef]

35. Witt, C. Transport packaging: Neat and clean or down and dirty. Mater. Hand. Eng. 1999, 54, 71-73.

36. Livingstone, S.; Sparks, L. The new German packaging laws: Effects on firms exporting to Germany. Int. J. Phys. Distrib. Logist. Manag. 1994, 24, 15-25. [CrossRef]

37. Kroon, L.; Vrijens, G. Returnable containers: An example of reverse logistics. Int. J. Phys. Distrib. Logist. Manag. 1995, 25, 56-68. [CrossRef]

38. Glock, C.H. Decision support models for managing returnable transport items in supply chains: A systematic literature review. Int. J. Prod. Econ. 2017, 183, 561-569. [CrossRef]

39. Kim, T.; Glock, C.H.; Kwon, Y. A closed-loop supply chain for deteriorating products under stochastic container return times. Omega 2014, 43, 30-40. [CrossRef]

40. Glock, C.H.; Kim, T. Container management in a single-vendor-multiple-buyer supply chain. Logist. Res. 2014, 7, 112. [CrossRef]

41. Kelle, P.; Silver, E.A. Forecasting the returns of reusable containers. J. Oper. Manag. 1989, 8, 17-35. [CrossRef]

42. Goh, T.; Varaprasad, N. A statistical methodology for the analysis of the life-cycle of reusable containers. IIE Trans. 1986, 18, 42-47. [CrossRef]

43. Lee, H.L. Lot sizing to reduce capacity utilization in a production process with defective items, process corrections, and rework. Manag. Sci. 1992, 38, 1314-1328. [CrossRef]

44. Gupta, T.; Chakraborty, S. Looping in a multistage production system. Int. J. Prod. Res. 1984, $22,299-311$. [CrossRef]

45. Tayi, G.K.; Ballou, D.P. An integrated production-inventory model with reprocessing and inspection. Int. J. Prod. Res. 1988, 26, 1299-1315. [CrossRef]

46. Lee, H.H.; Chandra, M.J.; Deleveaux, V. Optimal batch size and investment in multistage production systems with scrap. Prod. Plan. Cont. 1997, 8, 586-596. [CrossRef]

47. Glock, C.H.; Jaber, M.Y. Learning effects and the phenomenon of moving bottlenecks in a two-stage production system. Appl. Math. Model. 2013, 37, 8617-8628. [CrossRef]

48. Salameh, M.; Jaber, M. Economic production quantity model for items with imperfect quality. Int. J. Prod. Econ. 2000, 64, 59-64. [CrossRef]

49. Jaber, M.Y.; Zanoni, S.; Zavanella, L.E. Economic order quantity models for imperfect items with buy and repair options. Int. J. Prod. Econ. 2014, 155, 126-131. [CrossRef] 
50. Ouyang, L.Y.; Chen, C.K.; Chang, H.C. Quality improvement, setup cost and lead-time reductions in lot size reorder point models with an imperfect production process. Comput. Oper. Res. 2002, 29, 1701-1717. [CrossRef]

51. Cárdenas-Barrón, L.E. Economic production quantity with rework process at a single-stage manufacturing system with planned backorders. Comput. Ind. Eng. 2009, 57, 1105-1113. [CrossRef]

52. Eroglu, A.; Ozdemir, G. An economic order quantity model with defective items and shortages. Int. J. Prod. Econ. 2007, 106, 544-549. [CrossRef]

53. Ben-Daya, M. The economic production lot-sizing problem with imperfect production processes and imperfect maintenance. Int. J. Prod. Econ. 2002, 76, 257-264. [CrossRef]

54. Sarkar, B.; Majumder, A.; Sarkar, M.; Kim, N.; Ullah, M. Effects of variable production rate on quality of products in a single-vendor multi-buyer supply chain management. Int. J. Adv. Manuf. Technol. 2018, 99, 567-581. [CrossRef]

55. Sarkar, B. Mathematical and analytical approach for the management of defective items in a multi-stage production system. J. Clean. Prod. 2019, 218, 896-919. [CrossRef]

56. Kim, M.S.; Kim, J.S.; Sarkar, B.; Sarkar, M.; Iqbal, M.W. An improved way to calculate imperfect items during long-run production in an integrated inventory model with backorders. J. Manuf. Syst. 2018, 47, 153-167. [CrossRef]

57. Sett, B.K.; Sarkar, S.; Sarkar, B. Optimal buffer inventory and inspection errors in an imperfect production system with preventive maintenance. Int. J. Adv. Manuf. Technol. 2017, 90, 545-560. [CrossRef]

58. Sarkar, B.; Sett, B.K.; Sarkar, S. Optimal production run time and inspection errors in an imperfect production system with warranty. J. Ind. Manag. Optim. 2018, 14, 267-282. [CrossRef]

59. Kang, C.W.; Ullah, M.; Sarkar, B. Optimum ordering policy for an imperfect single-stage manufacturing system with safety stock and planned backorder. Int. J. Adv. Manuf. Technol. 2018, 95, 109-120. [CrossRef]

60. Khanna, A.; Kishore, A.; Sarkar, B.; Jaggi, C. Supply Chain with Customer-Based Two-Level Credit Policies under an Imperfect Quality Environment. Mathematics 2018, 6, 299. [CrossRef]

61. Tayyab, M.; Sarkar, B.; Ullah, M. Sustainable Lot Size in a Multistage Lean-Green Manufacturing Process under Uncertainty. Mathematics 2019, 7, 20. [CrossRef]

62. Tayyab, M.; Sarkar, B.; Yahya, B. Imperfect Multi-Stage Lean Manufacturing System with Rework under Fuzzy Demand. Mathematics 2019, 7, 13. [CrossRef]

63. Ullah, M.; Sarkar, B.; Asghar, I. Effects of Preservation Technology Investment on Waste Generation in a Two-Echelon Supply Chain Model. Mathematics 2019, 7, 189. [CrossRef]

(c) 2019 by the authors. Licensee MDPI, Basel, Switzerland. This article is an open access article distributed under the terms and conditions of the Creative Commons Attribution (CC BY) license (http://creativecommons.org/licenses/by/4.0/). 